\title{
"USTED ESTABA COMO CONFUCIO, ANDABA CONFUNDIDO”: HACIA UNA MIRADA CRÍTICA DE LOS DISCURSOS EVALUATIVOS ${ }^{1}$
}

\author{
Oscar Iván Londoño Zapata² \\ (Universidad de Ibagué - Colombia)
}

\begin{abstract}
The central purpose of this paper is to show some features found in the investigation called "Critical Analysis in the evaluative discourse maded by the Spanishlanguage teachers from years 10 and 11, in some educational institutions located in Ibagué (Colombia)", maded and finished in 2007. I develop this paper by presenting some general features as an introduction about the discursive research. After that, I present the theorical position that I use as an invesigation core to explain the analysis of the taken samples. I also show and explain the critical analysis of some discursive samples (oral and written); and as a final point, I present the conclution of the investigation and the bibliographic references used to do this paper.
\end{abstract}

Key Words: Critical Analysis Discourse (CAD), evaluative discourse, teachers, overuse of power, dominance.

\section{RESUMEN}

El propósito central de este artículo es dar a conocer algunos aspectos y hallazgos de la investigación: "Análisis crítico de los discursos evaluativos de los docentes de lengua castellana de los grados décimo $\left(10^{\circ}\right)$ y once $\left(11^{\circ}\right)$, de algunas instituciones educativas de Ibagué (Colombia)", realizada en el año 2007. Para llevar a cabo lo anterior, presento a manera de introducción algunos aspectos generales del estudio discursivo; en forma seguida, planteo la metodología y la postura teó-

1 Este artículo es construido con base en ponencia presentada en el VII Congreso Latinoamericano de Estudios del Discurso, celebrado en septiembre de 2007 en la Universidad Nacional de Colombia, en la Ciudad de Bogotá, por la Asociación Latinoamericana de Estudios del Discurso (ALED).

2 Docente e investigador del Area de Lenguaje de la Facultad de Humanidades, Artes y Ciencias Sociales de la Universidad de Ibagué (Tolima-Colombia). 
rica que empleo como eje investigativo y argumental del análisis de las muestras, presento el análisis crítico de algunas muestras discursivas evaluativas (orales y escritas); y en última instancia, las conclusiones y la bibliografía de referencia.

Palabras clave: Análisis Crítico del Discurso (ACD), discurso evaluativo, profesores, abuso de poder, dominación.

\section{Introducción}

El discurso, como proceso oral y escrito de interacción comunicativa, está presente en todas las prácticas socioculturales que (re)produce el ser humano, de ahí que su estudio no sólo sea responsabilidad de la lingüística, sino que requiere una articulación epistemológica con otras ciencias y disciplinas que faciliten la comprensión de este fenómeno contextual del lenguaje. Es por ello que surge la necesidad de interpretar los discursos desde variadas perspectivas, teorías y metodologías. El Análisis Crítico del Discurso (ACD) configura una de estas posibilidades de análisis. Una zona de contacto determinante en la develación de los vínculos existentes entre discurso, ideología, poder y sociedad.

A partir de lo anterior, presento en este artículo algunos aspectos y hallazgos de la investigación: "Análisis crítico de los discursos evaluativos de los docentes de Lengua Castellana de los grados décimo $\left(10^{\circ}\right)$ y once $\left(11^{\circ}\right)$, de algunas instituciones educativas de Ibagué”, en la que desarrollo el análisis crítico de los discursos orales y escritos que emplean algunos docentes de Lengua Castellana de los grados décimo $\left(10^{\circ}\right)$ y once $\left(11^{\circ}\right)$ de educación secundaria, en determinadas instituciones educativas del municipio de Ibagué (Tolima-Colombia), para evaluar las actividades académicas escolares de los estudiantes. Esta investigación tiene como objetivos: 1. Identificar las estructuras y estrategias discursivas orales y escritas que emplean los docentes para evaluar las actividades académicas escolares, y 2. Establecer los niveles de confiabilidad evaluativa de estos discursos. En este texto haré énfasis en la identificación y el análisis de las estructuras y estrategias lingüísticas que emplean los docentes para 
evaluar las actividades académicas escolares a través de sus discursos evaluativos orales y escritos.

La pertinencia de este estudio se justifica desde la importancia que posee la evaluación como práctica discursiva y pedagógica en la escena escolar. La evaluación es una valoración fundamental en los procesos de enseñanza-aprendizaje, no sólo de la lengua y la literatura, sino de todas las disciplinas y saberes en los que el ser humano se puede educar y formar. Por tanto, no es sólo una práctica mediada por instrumentos (pruebas o exámenes orales o escritos), para determinar cómo ha sido el avance del aprendizaje de los estudiantes, sino que es una práctica discursiva institucional y como tal está provista de una serie de mediaciones lingüísticas que determinan múltiples formas de interacción y subjetivación. Por tanto, teniendo en cuenta las particularidades de esta investigación, conceptualizo el discurso evaluativo como el discurso (oral y escrito) enunciado por el docente en el que valora cualitativamente una actividad académica escolar que ha realizado el estudiante por instrucción suya en el tiempo de clase o en casa.

\section{Metodología}

La investigación, que configura en su dimensión un estudio de casos, se realiza con base en un corpus conformado por doce muestras: siete secuencias de diálogo orales y cinco discursos evaluativos escritos de trabajos de estudiantes. Estas doce muestras discursivas se tomaron de un número mayor de muestras: 25. De esta manera, empleo siete muestras orales transcritas de diálogo institucional pertenecientes a diferentes macro-diálogos de clase. Es decir, cada una de las muestras orales analizadas resulta ser una secuencia discursiva significativa inserta en un acto discursivo mayor, que delimito por posturas teóricas y metodológicas para desarrollar el análisis mediante la selección al azar. Por tanto, transcribo 15 macro-diálogos de clase y de éstos selecciono siete secuencias discursivas de macro-diálogos diferentes para ser 
analizadas. Por su parte, para el análisis de los discursos evaluativos escritos empleo cinco discursos, seleccionados también al azar, de 10 trabajos realizados por algunos estudiantes y evaluados por los docentes.

Estas muestras discursivas pertenecen a dos docentes que orientan la asignatura Lengua Castellana en los grados décimo $\left(10^{\circ}\right)$ y once $\left(11^{\circ}\right)$ en dos instituciones educativas del municipio de Ibagué (TolimaColombia).

De la misma forma, teniendo en cuenta que uno de los objetivos de la investigación se orienta hacia la identificación y el análisis de las estructuras y estrategias lingüísticas y discursivas que emplean los docentes para evaluar las actividades académicas escolares, realizo un estudio lingüístico progresivo, que analiza cada muestra seleccionada (oral y escrita), siguiendo el orden de enunciación establecido por los interlocutores en el acto comunicativo. Así, de esta manera progresiva, presento los análisis de algunas muestras del corpus más adelante.

\section{Análisis Crítico del Discurso (ECD) y Discurso Evaluati- vo (DE)}

El Análisis Crítico del Discurso (ACD) es definido como el enfoque del Análisis del Discurso (AD) que analiza, critica y resiste sistemas de dominación y abuso de poder; aunque, para autoras como Luisa Martín Rojo, María Laura Pardo y Rachel Whittaker (1998) el "ACD no puede considerarse como una escuela más o una rama particular del análisis del discurso", debido a que adoptan las posturas de Teun A. van Dijk, así, agregan las autoras "se trata de una "perspectiva" distinta, un "modo" diferente de acercarse a la construcción de la teoría y a su aplicación en el análisis" (Martín Rojo, Pardo y Whittaker, 1998). Por tanto, es una perspectiva crítica y política que analiza cómo el discurso vehicula abuso de poder, dominación y control.

La dominación es definida por van Dijk (1994) como "la relación desigual entre grupos sociales que controlan otros grupos"; 
por consiguiente, "la dominación tiene que ver con las limitaciones de libertad que se ejercen sobre un grupo. Forma de abuso de poder del grupo dominante". De igual manera, en concepto de Adriana Bolívar (2005) "la dominación se entiende como abuso de poder que, a su vez, significa uso ilegítimo del poder, que se interpreta como la violación de principios (leyes, normas, reglas, etc.) justos, es decir, consistentes con derechos humanos y sociales". Por su parte, el abuso de poder también es definido por van Dijk (1994) como las "varias formas de ejercicio de poder inaceptables e ilegítimas, dadas en interacciones socialmente aceptadas que favorecen específicamente a los grupos con poder". Por tanto, es el uso ilegítimo del poder que un grupo dominante, con prácticas discursivas y sociales legitimadas institucionalmente, ejerce sobre un grupo dominado.

De esta manera, el Análisis Crítico del Discurso (ACD) es una zona de contacto que articula fundamentos de otras disciplinas para su interpretación discursiva. Esta actitud crítica se centra en los problemas sociales y en especial en el papel del discurso en la (re)producción del abuso de poder y la dominación. En concepto de van Dijk (1994) el ACD "permite elucidar las estrategias de uso, de legitimación y de construcción de la dominación enmarcadas en el abuso del poder”. De modo que, conceptos como: control, desigualdad, superioridad, ideología, autoridad, injusticia, sexismo, racismo, poder, dominación y cambio, son el eje conceptual estructurante de esta perspectiva y actitud crítica de análisis.

Al respecto, Norman Fairclough y Ruth Wodak (2000) plantean que "el ACD (Análisis Crítico del Discurso) interpreta el discurso - el uso del lenguaje en el habla y en la escritura - como una forma de "práctica social”; de ahí que dicha interpretación sugiera una relación determinante entre el evento comunicativo particular y las situaciones, instituciones y estructuras sociales que lo enmarcan. Por consiguiente, la producción discursiva, objeto de análisis, debe ser explicada, comprendida y analizada desde el contexto en el que se enuncia y desde el estatus y el rol sociocultural, institucional y discursivo del 
interlocutor; de esta forma, no es posible la producción de un discurso sin contexto así como no es posible su comprensión si no se toma en cuenta el contexto.

Por su parte, el Discurso Evaluativo (DE), como ya mencioné anteriormente, es el discurso (oral y escrito) enunciado por el docente en el que valora cualitativamente una actividad académica escolar que ha realizado el estudiante por instrucción suya en el tiempo de clase o en casa. De ahí que el discurso evaluativo valore cualitativamente, mediante una acción discursiva oral y escrita, las actividades académicas escolares de los estudiantes: actividades sugeridas en clase, tareas extra clase, exposiciones individuales y grupales, trabajos de consulta, trabajos escritos, talleres, cuestionarios, pruebas objetivas, entre otras. De esta forma, por su misma naturaleza institucional resulta un tipo de discurso idóneo para ser analizado mediante el Análisis Crítico del Discurso (ACD).

\section{Análisis de las Muestras Orales y Escritas}

Los análisis críticos que en este apartado se desarrollan permiten identificar y analizar de las diferentes estructuras y estrategias lingüísticas que emplean los docentes para evaluar las actividades académicas escolares. Cada muestra seleccionada (oral y escrita), se analiza siguiendo el orden de enunciación establecido por los interlocutores en el acto comunicativo.

\subsection{Muestra Oral Uno: ¿El cuaderno o la CPU?}

Profesor: "Se notaba que ustedes habían consultado, algunos tenían el cuaderno, pero yo difiero muchísimo de que la tarea sea para el cuaderno, yo en el cuaderno consigno lo que yo investigo, PERO yo debo registrarlo en mi CPU porque esa es la que yo cargo, de aquí a diez años usted en la universidad le preguntan algo y usted 
no puede decir ah eso está en mi cuaderno de décimo, el cuaderno se quedó en la casa la información que usted grabó en su CPU es la que le queda".

El docente evalúa con el anterior discurso una actividad académica escolar en donde los estudiantes de un grupo de trabajo leen del cuaderno el contenido de la temática que debían desarrollar para la clase. En esta secuencia discursiva es recurrente el empleo del yo, pronombre personal de la primera persona del singular de los dos géneros, partícula que no se sucede como una simple designación (el pronombre se emplea para designar una cosa o una persona sin mencionar su nombre), sino que adquiere una especial carga semántica y pragmática en esta enunciación; por tal razón, se establece una trasgresión del concepto lingüístico formal de la referencia debido a la fuerza ilocutiva de la emisión. Empleando esta estructura el docente expresa su posición dominante: "yo difiero..., yo en el cuaderno..., yo investigo..., yo debo registrarlo..., yo cargo...", en relación con los estudiantes. Por tanto, la repetición continua del pronombre personal -yo- en una enunciación discursiva evaluativa hace referencia al posicionamiento superior dominante de acción y conocimiento del interlocutor emisor.

Dicha posición se acentúa, además, con la utilización de partículas discursivas como usted y ustedes: "ustedes habian consultado..., ustedes en la universidad..., usted no puede decir..., en la información que usted grabó...”; de esta forma, se establece una relación de alejamiento pronominal generada a partir de los pronombres yo y usted (es), distanciamiento en el que el sujeto dominante: docente, reafirma su posición ante el sujeto dominado: estudiante; esta relación vertical, prototípica de la educación tradicional, se establece debido al rol y al poder que le es asignado al docente como formador por el Estado, la sociedad y la cultura, es decir, por su rol institucional y socio-cognitivo superior y privilegiado legitimado.

El Diccionario Enciclopédico Educativo Uno Coatenas define la estructura discursiva "usted" como una voz de tratamiento cortesano y familiar, un pronombre personal de segunda persona empleado como 
tratamiento de respeto; sin embargo, en el caso concreto, este sentido de cortesía, familiaridad y respeto se transforma, por la relación de alejamiento pronominal, así, el - usted (es) - no se enuncia por cortesía sino para definir los roles sociales e institucionales de los interlocutores y sus respectivas posiciones educativas: ¿Quién enseña?: docente-yo, ¿Quién aprende?: estudiante-usted(es); por tal motivo, la aparente cortesía verbal evidencia una manifestación sutil de dominación.

Al respecto, Jan Renkema (1999) plantea tres elementos institucionales importantes en los estudios del discurso: 1. La conducta a través de roles, 2. Las tendencias a la diferenciación y 3. El poder institucional. La institución controla y regula las conductas y las formas de acción social y discursiva a través de un sistema de roles sociales que deben cumplir los participantes, de manera que, "objetiviza a los individuos, transformándolos en actores con roles específicos" (Renkema, 1999). Cada sujeto educativo: docentes, docentes directivos y estudiantes, asumen y naturalizan una serie de conductas y roles institucionales legitimados que determinan sus actuaciones sociales y discursivas, orientadas hacia diferenciaciones dominantes sustanciales. Renkema (1999) propone un ejemplo que ilustra este elemento: "Un ejemplo son las normas que regulan las interrupciones. Un docente puede interrumpir fácilmente a un estudiante, pero es más difícil que el estudiante interrumpa al profesor".

Por su parte, la institución regula las conductas, específicamente las de los escolares, a través de sistemas de normas educativas, pedagógicas y didácticas, y ejerce poder por medio de éstas; dicha modalidad de poder amplía el área de dominio y control, abuso de poder que es eminentemente discursivo, porque es ejercido a partir del uso concreto de la lengua. Al respecto, Neyla Graciela Pardo Abril (2001) plantea que:

"Las manifestaciones más sutiles y aparentemente no intencionales de la dominación, pueden ser observables, por ejemplo, en la entonación, el estilo sintáctico o léxico, las figuras retóricas, las estructuras locales semánticas, las estrategias de la toma de turno, la estructura de los pares dialógicos o en las distintas formas de cortesía verbal”. 
Teniendo en cuenta lo anterior, el docente construye el discurso evaluativo desde su propio protagonismo: yo, de tal manera que expresa a los estudiantes lo que él hace o debe hacer: "yo en el cuaderno consigno lo que yo investigo, yo debo registrarlo en mi CPU porque es la que yo cargo". Lo anterior con la finalidad de posicionarse como sujeto de ejemplo, característica fundamental del modelo pedagógico tradicional en donde el docente es el modelo y guía al que se debe seguir, imitar y obedecer.

Otra marca pronominal que acentúa la posición dominante y la relación de alejamiento es el " $m i$ ", forma del pronombre personal de la primera persona singular: "yo debo registrarlo en mi CPU", este pronombre indica pertenencia; a su vez, la marca "su”, también pronombre de pertenencia, refuerza el sentido de distancia: "la información que usted grabó en su CPU". Con base en lo anterior, planteo la construcción del cuadro de alejamiento pronominal como una estrategia para el análisis de los dispositivos de distanciamiento discursivo y social de los interlocutores, en el campo del ACD:

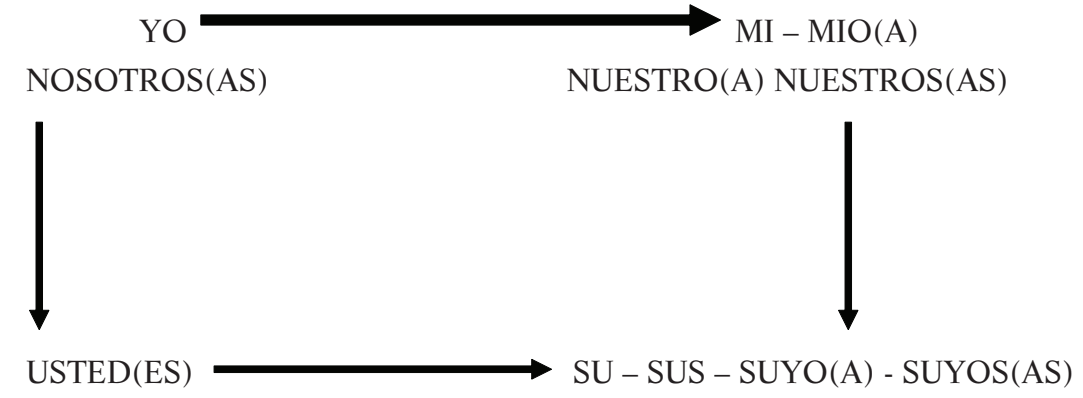

Este cuadro permite analizar la lógica de las estrategias de polarización discursiva de alejamiento pronominal dominante entre los interlocutores en la interacción comunicativa, a partir del empleo de pronombres personales: de cercanía: yo, nosotros(as), y de lejanía: usted(es). Y pronombres posesivos o de pertenencia: por cercanía: $m i$, mío(a), míos(as), nuestra(o), nuestras(os), y por lejanía: su, sus, suyo(a), 
suyas(os). Los pronombres personales -yo, nosotros(as)- guardan estrecha relación con los pronombres posesivos por cercanía, debido a que referencian las marcas discursivas del interlocutor dominante, sujeto del distanciamiento en la situación comunicativa; a su vez, el pronombre personal usted, y su plural, guardan también directa relación con los pronombres posesivos por lejanía debido a que son las marcas discursivas enunciadas por el interlocutor dominante sobre el individuo objeto del distanciamiento.

En esta medida, considero importante realizar estas especificaciones pronominales porque aunque aparentemente son empleadas por los docentes como formas naturales de expresión, y en general por todas las personas, las lógicas de enunciación determinan sus implicaciones determinantes en la dominación y el abuso de poder; esto debido a que, en el particular caso, se enuncian para diferenciar, alejar y determinar roles educativos. Al respecto, Michael Meyer (2003) plantea que "En principio, podemos asumir que las categorías como la deíctica y la de los pronombres pueden ser analizadas mediante cualquier método lingüístico, pero debe tenerse en cuenta que resultan cruciales para el ACD”.

Cuando el docente enuncia: "yo difiero muchísimo de que la tarea sea para el cuaderno", no solamente expresa su rol dominante desde el empleo del pronombre yo, sino que usa el término -muchísimo-, un adverbio de cantidad expresado en el grado más alto o superlativación absoluta, que contribuye al sentido de superioridad dominante; por tanto, es el profesor quien, en gran medida, no está de acuerdo.

En su discurso el docente emplea estructuras de lo que la tecnología ha denominado "lenguaje informático"; de esta manera, asimila el cerebro humano a la Unidad de Procesamiento Central o CPU de la computadora: "yo debo registrarlo en mi CPU porque esa es la que yo cargo, la información que usted grabó en su CPU es la que le queda"; lo anterior especifica que el docente posee una representación mecanicista de la producción intelectiva y cognitiva del ser humano, reduciendo dichos procesos al sólo registro y grabación de datos o información, 
característica fundamental del modelo pedagógico tradicional o de educación bancaria en términos del pedagogo brasileño Paulo Freire (1985), en donde la memorización y el registro de los datos son una de las funciones centrales del aprendizaje. Para Freire (1985) "la narración (principal género discursivo empleado por el docente) los transforma ( a los estudiantes) en "vasijas", en recipientes que deben ser "llenados" por el educador. Cuando más vaya llenando los recipientes con sus "depósitos", tanto mejor educador será. Cuanto más se dejen llenar dócilmente, tanto mejor educandos serán”.

\subsection{Muestra Oral Dos: Usted estaba como Confucio, andaba confundido Convenciones:}

\section{P: $\quad$ Profesor}

E1: Estudiante uno

E2: Estudiante dos

\section{(...): Tiempo en segundos}

P: ¿Cuál era la pregunta que tenía que responder?

E1: Pueblos aborígenes (de la Península Ibérica)

P: $\quad$ Pueblos aborígenes, vuélvalos a leer

E1: El italiano

P: $\quad$ Bueno, un pueblo aborigen de la Península Ibérica es el pueblo italiano (2)

E1: El provenzal, español, catalán, portugués, francés

P: $\quad$ Un pue un idioma aborigen y un pueblo aborigen de la Península Ibérica es el francés iestará bien?

E2: $\quad$ No

P: $\quad$ ¿Un pueblo de la Península Ibérica es el pueblo italiano y el pueblo francés? Estamos hablando de la Península Ibérica y en la Península Ibérica en la época en que nos estamos refi- 
riendo eran los pueblos de la Iberia y en la Iberia estaba la lusitania que hoy en día es portugués, hablan el portugués pero es Portugal, ¿de acuerdo?, toes su tarea no está bien ¿Qué pasó?

E1: Nos confundimos

P: $\quad$ Nos confundimos, usted estaba como Confucio andaba confundido.

El docente asigna una actividad académica escolar para ser trabajada en grupos y al momento de socializar el trabajo en clase un estudiante relator de uno de los grupos lee lo realizado. En esta secuencia de diálogo institucional el docente evalúa la respuesta del escolar desde una ironía discursiva por repetición: el estudiante lee la respuesta de la pregunta y el docente ironiza dicha respuesta a partir de la misma en dos ocasiones.

El docente ordena al escolar que vuelva a leer la respuesta: "Pueblos aborígenes, vuélvalos a leer", el escolar inicia: "El italiano", inmediatamente el docente reconoce el desacierto y no hace la respectiva aclaración sino que afirma, arrebatando el turno, aún más la respuesta, y por ende, el desacierto del escolar: "Bueno, un pueblo aborigen de la Península Ibérica es el pueblo italiano”.

Inicia la evaluación con el término -bueno-, adjetivo que generalmente califica en forma positiva; sin embargo, en el caso específico califica en forma negativa debido a que el significado de esta cualidad cotidiana se contradice, porque el contenido del enunciado siguiente: "un pueblo aborigen de la Península Ibérica es el pueblo italiano", no es correcto. La estrategia lingüística con la que construye este enunciado contribuye también a la ironía discursiva, es decir, en esta oración el docente enuncia primero el predicado: "un pueblo aborigen de la Península Ibérica", y después el verbo y el sujeto: "es el pueblo italiano"; la anterior forma de alteración sintáctica proporciona una mayor carga semántica y pragmática de ironía, y desacierto al contenido del enunciado, aspecto que se acentúa aún más por su carácter afirmativo. 
Al respecto, Alain Berrendonner (1981) plantea que "la ironía es un procedimiento que superpone a un determinado valor argumentativo el valor contrario, juzgado más acorde”. De esta manera, la ironía tiene lugar cuando lo dicho explícitamente en un enunciado se halla desmentido por una información situacional o contextual implícita, de tal modo que al firmar A, se sugiera no-A (Escamilla, 1998). Al afirmar el docente: "un pueblo aborigen de la Península Ibérica es el pueblo italiano", lo que sugiere el contenido real del discurso evaluativo es: -el pueblo italiano no es un pueblo aborigen de la Península Ibérica-. Por tanto, la ironía discursiva del juicio evaluativo es una "Trasgresión de la Ley de Sinceridad” (Kerbratt-Orecchioni, 1984).

El escolar continúa ante el silencio del docente: "el provenzal, español, catalán, portugués, francés", este último término hace que el docente evalúe de la misma forma discursiva la respuesta: "un pue un idioma aborigen y un pueblo aborigen de la Península Ibérica es el francés"; así, se establece también la alteración sintáctica que contribuye al sentido ironizante del discurso evaluativo. En concepto de Neyla Graciela Pardo Abril (2001):

"En las estructuras discursivas, la relación poder-discurso se puede explicar al poner en evidencia ciertas propiedades de la sintaxis y la morfología... la sintaxis marca relevancia, énfasis, disimulo y ocultamiento al formular desde el discurso, el orden y la posición jerárquica a los juicios o proposiciones expresadas; la posición y la función preposicional marcan presupuestos e implicaciones, que completan o modifican el sentido final del discurso".

Por tanto, el discurso evaluativo presenta una característica de modalidad reiterativa dominante de ironía a partir de alteraciones en la sintaxis.

En forma seguida el docente pregunta: “Estará bien?”, y otro estudiante responde: "no", ante la confirmación pública del desacierto, el docente realiza la pregunta: “ ¿Un pueblo de la Península Ibérica es el pueblo italiano y el pueblo francés?” Esta interrogación se construye 
sobre la misma alteración sintáctica, aunque disminuye algunos grados de ironización discursiva debido a su forma interrogativa. Por ende, puedo plantear que los grados de ironización discursiva aumentan o disminuyen según el tipo de enunciación.

El docente enuncia una explicación teórica con el fin de dar respuesta a la pregunta que él mismo formuló anteriormente, y en general a la que el grupo debía responder. Por esta razón, son dos las preguntas que desde mi perspectiva requieren aclaración teórica:

- ¿Cuáles son los pueblos aborígenes de la Península Ibérica?

- ¿Por qué el pueblo italiano y el pueblo francés no son pueblos aborígenes de la Península Ibérica?

La explicación que da el docente aclara el tema: "estamos hablando de la Península Ibérica" y expresa algunos atributos de su significado: "la Península Ibérica en la época en que nos estamos refiriendo eran los pueblos de la Iberia", a continuación da atributos de la Iberia: "y en la Iberia estaba la lusitania que hoy en día es portugués, hablan el portugués pero es Portugal". La explicación teórica no da respuesta directa a las preguntas que necesitan aclaración; por tanto, no menciona los pueblos aborígenes de la Península y no da los motivos geográficos, históricos y socioculturales por los cuales Francia e Italia no son pueblos aborígenes de la Península Ibérica.

Este bajo nivel de confiabilidad académica (disciplinar) se evidencia además discursivamente por el empleo de la partícula -estamos-: "estamos hablando", "nos estamos refiriendo"; de esta manera, el docente emplea un -nosotros- que involucra a los demás estudiantes para expresar la explicación teórica; el nosotros se enuncia como una marca de un locutor múltiple, constituyendo así lo que Patrick Charaudeau (1992) ha denominado: "un locutor colectivo". Dicha estrategia discursiva referencia un bajo grado de seguridad en lo que se enuncia, debido a que cuando un interlocutor enuncia desde el -yo-: "yo estoy hablando, estoy hablando, yo me estoy refiriendo", me estoy refiriendo, denota y connota mayores niveles de seguridad teórica y, por ende, de confiabilidad 
académica; aunque, dejo en claro que esta estructura pronominal: -yo, enunciada desde una modalidad reiterativa, referencia un grado de superioridad dominante.

Después de la explicación el docente hace una pregunta al escolar: “¿de acuerdo?”, pero, no permite que éste de su respuesta, así, el estudiante no da su opinión sobre lo que dice el docente. En forma seguida expresa: "toes su tarea no está bien"; si bien es cierto que la tarea del estudiante posee una serie de desaciertos, la explicación teórica del docente no es fundamento confiable para sustentar este juicio evaluativo. Además, al especificar la respuesta del escolar sólo tres conceptos no guardan relación aborigen con la Península Ibérica: -italiano, provenzal y francés-, por lo que es pertinente plantear la siguiente pregunta: ¿Por qué el docente no evaluó de la misma manera cuando el escolar propuso el provenzal como pueblo aborigen de la Península Ibérica? Lo anterior se debe al desconocimiento por parte del docente de la procedencia del provenzal.

A continuación el docente pregunta: “Qué pasó?”, solicitando una razón que justifique la equivocación, el estudiante responde: "nos confundimos", incluyendo a sus demás compañeros de trabajo, el docente repite la respuesta: "Nos confundimos", y prosigue: "usted estaba como Confucio andaba confundido", el anterior juicio está dirigido al relator únicamente: -usted-, y no vincula a los demás estudiantes del grupo en el discurso evaluativo; por tanto, hace ver que es el estudiante relator quien no contestó bien la pregunta; a partir de lo anterior, planteo que el enunciado evaluativo posee, además, bajos niveles de confiabilidad porque se dirige a una persona específica, siendo varios los participantes del grupo de trabajo.

El docente construye este juicio de valor empleando una expresión popular: "usted estaba como Confucio andaba confundido", enunciación que posee intertextualidad con el filósofo chino Confucio, creador del confucionismo y una de las figuras más determinantes en la historia política y filosófica de China; sin embargo, el contenido real de este discurso no se dirige a desatacar alguna característica del pensador 
oriental reflejada en el escolar, sino a establecer la identidad fonética que poseen los términos Confucio y confundido: C-O-N-F-U-cio - C-ON-F-U-ndido, esta cacofonía parcial resulta ser cómica por su efecto perlocutivo: risas en los demás compañeros(as), aspecto que contribuye a la ironía y a la burla en el discurso evaluativo.

Por otra parte, es importante observar que la secuencia discursiva analizada anteriormente se genera a partir de una pregunta directa realizada y controlada por el docente, característica fundamental de la toma de turnos en el diálogo institucional en la escuela.

Este sistema de toma de turnos se aleja de la forma como se genera la toma de turnos en la conversación, por ello, las interacciones en las aulas (McHoul, 1978, 1990), presentan modelos de toma de turnos especiales que estructuran poderosamente aspectos de la conducta en estos marcos sociales; al respecto, Paul Drew y Marja-Leena Sorjonen (2000) plantean que:

"Estos sistemas de toma de turnos involucran una distribución diferencial de los tipos de turnos entre los participantes; en particular, las interacciones están organizadas en términos de secuencias de pregunta respuesta, en las que la interrogación se asigna al profesional (abogado, entrevistador, docente) y las respuestas al "cliente" (testigo, entrevistado, alumno)".

Siguiendo las concepciones de Teun A. van Dijk (1994), a partir de sus análisis sobre el control de las estrategias discursivas, la selección de los turnos es una estructura de interacción susceptible de ser controlada, así, el docente es el que determina quién comienza el diálogo, quién lo puede continuar o quién lo puede cerrar. Y de la misma manera, quién no puede participar en la interacción.

En este contexto, la modalidad de diálogo que determina la interacción comunicativa entre docente-estudiantes, el diálogo institucional, se construye a partir de una secuencia triple. Este tipo de secuencia es característica de la interacción entre docentes y estudiantes, según las investigaciones realizadas por Hugh Mehan (1979). Mehan llama a esta secuencia, secuencia de iniciativa/reacción/evaluación; 
de esta manera, la iniciativa corresponde a la pregunta que formula el docente, la reacción a la respuesta que da el/la escolar y la evaluación es la valoración que enuncia el docente de la iniciativa/reacción. Según el autor, la secuencia tripartita está conformada por dos pares adyacentes: el primer par es iniciativa/reacción, este par es la segunda parte del par evaluador, cuya función es valorar la relación entre iniciativa/reacción.

Por su parte, en concepto de Sinclair y Coulthard (1975), la forma de organización de los turnos de habla o de la participación en la clase entre docente y estudiantes es la estructura de intercambio IRF: Inicio, Respuesta y Feedback o Evaluación, estrategia similar a la de Mehan. Los autores también hacen referencia a que al docente corresponde el rol de ser regulador de los turnos de palabra y del tiempo de las intervenciones, siendo además, el iniciador del intercambio discursivo.

De igual manera, para Louise Dabène (1980), el diálogo pedagógico es un discurso de encerramiento. Dicha expresión fue sugerida en Ámsterdam en 1980 durante un coloquio de Lingüística en la línea de Lingüística Textual o Textolingüística y Pragmática. Para Teun A. Van Dijk (1980) los discursos de encerramiento son las interacciones empleadas en medios cerrados y fuertemente institucionalizados: escuelas, hospitales, ejercito, policía, y que presentan características comunes.

Según Dabène (1980), "el diálogo pedagógico es considerado como un discurso del encerramiento en la medida en que sus rasgos específicos están determinados por la situación de clase"; de esta forma, en los intercambios del medio escolar los interlocutores son definidos exclusivamente por sus roles y funciones respectivas, estas funciones indican toda una serie de derechos y deberes recíprocamente admitidos, pero que, en el caso de los estudiantes, son a menudo violentados.

$\mathrm{Al}$ respecto, este autor plantea que:

"Es cierto que la mayor parte de los docentes tienen una visión falsa de lo que se produce efectivamente en la clase: sobrevaloran por lo general las intervenciones de los alumnos y tienden a rechazar ciertas producciones, y en especial aquellas que no están directamente centradas en el objeto mismo de la lección” (Dabène, 1980). 


\subsection{Muestra Escrita Uno: Un trabajo sin sustentación no vale la pena}

Profesor: "Jóvenes, lo bueno de este trabajo era que hubieran ido a la fuente es decir leer el texto del lazarillo para que sacaran sus propias conclusiones. Además un trabajo esento sin sustentación realmente no vale la pena.

Esta reseña la he leído más de 10 veces todos tienen lo mismo".

El trabajo que evalúa el docente desarrolla diferentes aspectos de la Novela Picaresca, uno de los géneros más representativos y populares de la literatura española que posteriormente derivó hacia la novela de aventuras o cuadros de costumbres. Este tipo de narraciones utiliza el esquema tradicional de los libros o novelas de caballería, pero lo hace con una voluntad claramente desmitificadora, a partir de la crítica a la sociedad de la época.

En la parte superior izquierda de la portada el docente escribe con lapicero rojo el discurso evaluativo mayor: "Jóvenes, lo bueno de este trabajo era que hubieran ido a la fuente es decir leer el texto del lazarillo para que sacaran sus propias conclusiones. Además un trabajo esento (La forma correcta es exento) sin sustentación realmente no vale la pena"; nótese que es recurrente en los docentes el empleo del mismo espacio para la escritura del discurso evaluativo mayor, así como el color de la letra. Defino el juicio que generalmente aparece escrito en la portada del trabajo como el discurso evaluativo mayor, que agrupa los aspectos generales evaluados del contenido, es decir, el entramado conceptual plasmado por el/la estudiante, y la forma, es decir, la estructura textual y discursiva, del trabajo, acertados y desacertados. Los discursos evaluativos menores, por su parte, aparecen en el desarrollo del trabajo y también se orientan hacia la evaluación de los mismos aspectos; por ende, se evalúa contenidos: conceptuales, procedimentales y actitudinales.

La secuencia discursiva inicia con un llamado: "Jóvenes" y anexa: "lo bueno de este trabajo era que hubieran ido a la fuente". El docente expresa 
el requisito principal que debían cumplir los estudiantes para que el trabajo fuera "bueno": "leer el texto del lazarillo para que sacaran sus propias conclusiones"; de esta forma, para el docente los escolares no abordaron el texto del Lazarillo de Tormes, debido a que no encuentra referencias directas ampliadas de esta obra, de ahí el juicio evaluativo que escribe.

El trabajo de los escolares incluye temas globales de la novela picaresca como: el contexto social en que se origina, la novela picaresca española, las características de la novela picaresca: protagonista, orientación realista y satírica, tendencia moralizante, el humor pesimista, la intención didáctica, la estructura narrativa y las principales novelas picarescas; teniendo en cuenta lo anterior, los estudiantes desarrollan una visión general de este tipo de novela; por tanto, la observación del docente no posee altos niveles de confiabilidad evaluativa, debido a que los escolares plantearon conceptos coherentes con el tema del trabajo, así, desarrollaron el objetivo del mismo: "dar una visión general sobre la novela picaresca" y no la visión del Lazarillo de Tormes en particular. Por tanto, el docente debe tener en cuenta el objetivo del trabajo porque éste determina el desarrollo del mismo.

En esta medida, aunque los estudiantes se basaron en otros textos, que especifican en la bibliografía del trabajo y que son recomendados por el docente: Español sin fronteras 10. Pág. 82-83; Español dinámico 10. Pág. 103; Talento 10. Pág. 89-91, lo planteado es coherente con el tema que el mismo profesor especificó para el trabajo de consulta.

El docente escribe también: "Además un trabajo esento sin sustentación realmente no vale la pena”, lo anterior referencia que el trabajo no sólo debía realizarse sino también sustentarse, actividad que los estudiantes no desarrollaron, de ahí que el trabajo para el docente -no valga la pena-, con esta expresión excluyente, porque "todo trabajo que no se sustente no vale la pena”, el docente anula por completo y en forma ofensiva el trabajo de los estudiantes.

En el apartado del "Contexto Social" de la novela picaresca los escolares escriben: "la picaresca se inicio a mediados del siglo XVI con la publicación de el Lazarillo de Tormes (1554)”, encima de esta 
referencia histórica el docente escribe: "Esta reseña la he leído más de 10 veces todos tienen lo mismo". Lo anterior resulta obvio porque los escolares han tomado como fuente de consulta los mismos textos guía, recomendados por el docente, es decir, han realizado un plagio colectivo.

El anterior juicio evaluativo se estructura en dos enunciados: el primero "Esta reseña la he leído más de 10 veces", expresa en términos de cantidad las veces que el docente ha leído la reseña, aspecto que da fuerza al enunciado; lo anterior no sólo se referencia a nivel de contenido, son muchas las veces que ha leído lo mismo, sino que a nivel de estructura discursiva también se hace un énfasis, es decir, al subrayar la expresión: "10 veces" refire una fuerte carga de enunciación. Por tanto, las formas de enunciación con cargas semánticas y pragmáticas suceden tanto en la oralidad como en la escritura, así, en la oralidad se especifican a través de la entonación (también a partir de otras estrategias como la repetición, etc.), y en la escritura a partir del subrayado, el registro en mayúscula sostenida o la escritura en gran tamaño. Aunque, dejo en claro que las lógicas de la estructura del discurso, tanto oral como escrito, también referencian marcas de fuerza semántica y pragmática.

Por su parte, el segundo juicio, “...todos tienen lo mismo” hace referencia a que todos, partícula de generalización, escribieron la misma reseña, aspecto que connota el ya mencionado plagio colectivo o copia masiva. Teniendo en cuenta que la anterior forma de la intertextualidad (Genette, 1989), es una actividad recurrente en los estudiantes, este ejercicio discursivo debe llevar al docente a la reflexión sobre su quehacer pedagógico y disciplinar, es decir, el docente debe cuestionarse por el hecho que los estudiantes no realicen procesos de reformulación teórica, sino que privilegien la copia del libro u otra fuente textual. Por lo que, ¿Qué factores influyen en la falta de procesos de reformulación textual en los estudiantes? ¿Serán apropiadas o no las estrategias de recepción y producción textual que orienta el docente? ¿Consultar significa plagiar o consultar significa leer, comprender, interpretar y reformular? Preguntas de importancia que aportarían a la construcción de discursos evaluativos diferentes, con mayores niveles de confiabilidad. 
A partir de lo anterior, el discurso evaluativo no se orienta a la evaluación del contenido real del trabajo sino que expresa opiniones excluyentes en las que el docente anula por completo y en forma ofensiva el trabajo de los estudiantes, lo que determina su bajo nivel de confiabilidad evaluativa.

\subsection{Muestra Escrita Dos: No llena la más mínima expectativa}

Profesor: Ese trabajo que USTEDES presentan no llena la más mínima expectativa. Perdieron todo su tiempo en la realización.

INSUFICIENTE

Con el anterior discurso evaluativo mayor, escrito con lapicero rojo en la parte central de la portada, el docente valora un trabajo de consulta de cuatro estudiantes sobre la novela picaresca, en general los escolares especifican de manera breve aspectos como: definición, contexto social en el que surge este tipo de literatura y representantes. El docente no enuncia ningún tipo de discurso menor, solamente corrige los desaciertos ortográficos, lo que referencia su atención a estas reglas para el adecuado uso de las letras y otros signos de la escritura.

El docente inicia el discurso evaluativo con la partícula discursiva "Ese", referencia demostrativa por lejanía que indica un sentido despectivo por el trabajo de los escolares: "Ese trabajo que...", en forma seguida escribe la palabra: "USTEDES” en mayúscula sostenida, lo que refiere un distanciamiento social y discursivo cargado de una gran fuerza semántica y pragmática por el registro en mayúscula. La estructura que sigue: “...presentan no llena la más mínima expectativa", también se orienta hacia una acepción, que desde las partículas "más mínima", se carga de sentidos despreciativos; así, el trabajo realizado por los escolares es anulado completamente en términos actitudinales: el trabajo no llena la más mínima: esperanza, posibilidad, ilusión... 
El anterior juicio posee bajo niveles de confiabilidad porque las actividades académicas escolares no se valoran en términos actitudinales, lo que no impide que se evalúen actitudes, sino que deben ser valoradas en términos más conceptuales, es decir, más académicos; de ahí que la docente no plantee en el trabajo ningún juicio que valore los contenidos conceptuales y procedimentales. Es el discurso del silencio, aspecto que contribuye al bajo nivel de confiabilidad evaluativa.

Sin embargo, resulta interesante esta forma evaluativa a la que denomino modalidad actitudinal evaluativa, es decir, al expresar el discurso en términos actitudinales y tímicos, se impregna la enunciación de mayor emotividad, así, al expresar: "no llena la más mínima expectativa", refiere: no hay esperanza, no hay ilusión, no hay posibilidad. Por tanto, no hay nada. Juicio que afecta en forma directa el sistema emotivo y tímico de los estudiantes.

Por su parte, la expresión, que denota el alejamiento pronominal (su), "Perdieron todo su tiempo en la realización", contribuye al sentido de anulación del trabajo; de esta manera, los estudiantes perdieron el tiempo porque el trabajo no llena la más mínima expectativa, partícula que generaliza y afirma el "desacierto del trabajo". El discurso evaluativo finaliza con la valoración reglamentada: "INSUFICIENTE", término escrito con una fuerte carga semántica y pragmática debido a su registro en mayúscula.

\subsection{Muestra Escrita Tres: Ustedes no nacieron para estudiar}

Profesor: Sin duda alguna ustedes no nacieron para estudiar. Los niños de preescolar lo hubieran hecho mejor. No vale la pena corregir.

DEFICIENTE

Ese discurso evaluativo mayor, escrito con lapicero azul en la parte superior izquierda de la portada, valora una consulta realizada por cinco estudiantes de grado once sobre la lectura y la escritura. Los estudiantes presentan de manera breve algunos atributos de los conceptos de estos 
procesos del lenguaje. Al igual que en el trabajo anterior, el docente no enuncia ningún tipo de discurso evaluativo menor, solamente corrige los desaciertos ortográficos; además, aunque sea en un color diferente al rojo, azul, conserva la necesidad de diferenciar y determinar los registros y los roles de los sujetos.

El docente inicia el discurso evaluativo con la expresión: "Sin duda alguna ustedes no nacieron para estudiar", que referencia un distanciamiento discursivo y social, "ustedes", y que se semantiza y pragmatiza de acepciones de exclusión despectivas. Con este juicio el docente anula por completo las aptitudes y actitudes de los estudiantes para el estudio, "no nacieron para estudiar", afirmando que los escolares nacieron para llevar a cabo otras actividades menos la de desarrollar un proceso educativo escolar, lo que resulta ser una enunciación no sutil sino directa de exclusión y segregación escolar, y por ende, de dominio y abuso de poder.

La anterior estrategia discursiva resulta ser una estructura impregnada de modalidad de mentira irónica dominante. Para Durandin (1983), la mentira, definida con relación a la verdad, "consiste en dar voluntariamente a un interlocutor una visión de la realidad diferente de la que uno mismo tiene por verdadera”, así, lo que el docente enuncia a los escolares, es decir, que "no nacieron para estudiar", es una visión de la realidad diferente y falsa, no sólo de la que él mismo tiene, sino también de la realidad objetiva misma, debido a que no existen seres humanos que no nazcan para estudiar, a excepción de las personas que nacen con anomalías físicas, mentales y cognitivas, patologías no presentes en estos estudiantes, que les impida desarrollar hasta el más mínimo aprendizaje.

En este contexto, el nacer siendo humanos, con predisposición para desarrollar el lenguaje, y por ende el pensamiento, para aprender una lengua y evolucionar en una cultura y en una sociedad, garantiza la existencia de diferentes potencialidades para aprender y para educarse, derecho fundamental de los individuos, sea cual fuere el nivel de desarrollo social y madurativo, fundamentos conocidos por el docente de Lengua Castellana, y verificados por mí a través de conversaciones con él en el transcurso del tiempo de recolección de las muestras del corpus. 
Aunque, la mentira se enuncia con el propósito de ejercer en el otro interlocutor una influencia que modifique sus opiniones o comportamientos, buscando así obtener un grado de credibilidad en el interlocutor, más que para modificar opiniones y conductas, en el caso especifico, es enunciada para excluir y segregar a los estudiantes y, por tanto, su trabajo.

En forma seguida el docente escribe: "Los niños de preescolar lo hubieran hecho mejor.”. Con este juicio el docente ubica el desarrollo conceptual y cognitivo de los estudiantes de grado once (16-18 años de edad aproximada) en un nivel intelectivo menor que el de los niños de preescolar, uno de los primeros grados de escolaridad iniciado a los 5 años de edad, aproximadamente, debido a que éstos "lo hubieran hecho mejor.”. Lo que refiere un juicio con acepciones involutivas despectivas, debido a que el docente deja clara la aparente "incompetencia" e "imposibilidad" de los estudiantes para desarrollar dicho trabajo, aspecto que contribuye a la carga de sentido exclusiva de la primera enunciación; de esta manera, el contenido real del discurso referencia que "los estudiantes no nacieron, no sirven, para estudiar porque son incompetentes, no tienen posibilidades de hacer el trabajo”. Por tal motivo, el discurso evaluativo posee bajos niveles de confiabilidad porque se impregna de exclusión y dominación, y porque no evalúa contenidos.

Teniendo en cuenta lo anterior, es claro para el docente que "No vale la pena corregir.", de ahí que su valoración reglamentaria "DEFICIENTE”, el más bajo valor cargado de abuso en la evaluación, expresión enunciada con una fuerte carga semántica debido a su registro de mayor tamaño en mayúscula.

\subsection{Muestra Escrita Cuatro: ¿De quién es la responsabilidad?}

Profesor: ¿De quién era la responsabilidad?

Era responsabilidad de USTEDES aprender la temática y no lo hicieron.

Trabajo muy corto, lo mínimo eran 20 páginas.

Trabajo muy DEFICIENTE 
Con ese juicio evaluativo mayor, localizado en la sección superior derecha de la portada, el docente valora un trabajo de consulta sobre el origen del castellano realizado por cuatro estudiantes de grado décimo. El discurso conserva la relación de alejamiento pronominal, "USTEDES", no sólo desde el empleo del pronombre -usted(es)- sino desde su fuerza enunciativa. Lo anterior por el registro en mayúscula; además, la diferencia del color en el registro de la escritura también contribuye a dicha acepción.

El docente inicia el discurso evaluativo con una enunciación interrogativa: “¿De quién era la responsabilidad?”, dirigida a los estudiantes del trabajo; sin embargo, la respuesta es dada por el mismo interlocutor: "Era responsabilidad de USTEDES aprender la temática y no lo hicieron.", ésto con la finalidad que no sea aceptada otra respuesta, así, la única válida es la que el docente expresa. De esta manera, la visión pedagógica que posee el profesor, y que determina en su discurso, se orienta hacia la representación de los estudiantes como únicos responsables del proceso de aprendizaje de la temática, de tal forma, si los conocimientos no son aprendidos, no es el docente el responsable sino los escolares.

De esta manera, comparto con el docente la actitud y acción responsable del escolar como condición fundamental para el aprendizaje; sin embargo, los docentes no deben "desentenderse" del proceso de aprendizaje. De tal forma, si después de realizadas las actividades académicas los escolares no logran asimilar la temática, es preciso que los docentes desarrollen acciones estratégicas de re-conceptualización para que el aprendizaje sea significativo y los contenidos se acomoden de una manera creativa y duradera.

A continuación, el docente escribe: "Trabajo muy corto, lo mínimo eran 20 páginas.", haciendo referencia a la extensión del trabajo realizado por los estudiantes. Dicha brevedad es, para el docente, una característica del texto que contribuye al aparente desacierto de la actividad académica escolar, así, -el trabajo es incorrecto o está incompleto porque es corto-. No obstante, es preciso plantear que la extensión no determina en forma 
directa la calidad de los textos; de esta manera, un texto puede ser corto y contener la información necesaria y relevante para que sea cualificado en forma positiva. Valoraciones explícitas como las que enuncia el docente referidas a la extensión como parámetro principal de evaluación del texto, surgen de la visión cuantitativa de la escritura, es decir, a mayor cantidad de páginas, mayores alternativas de evaluar en forma positiva los trabajos. ¿Dónde quedan entonces los planteamientos conceptuales y procedimentales de los estudiantes? ¿En la extensión?

De tal forma, estas concepciones tradicionales y bancarias, más que valorar un proceso de escritura, buscan ejercitar la caligrafía, de ahí que no se establezcan discursos evaluativos que valoren los conceptos y los procedimientos o las formas textuales y discursivas con las que los estudiantes dan a conocer el saber. Con ello se relega en forma total las posiciones teóricas y académicas de los escolares, debido a que lo relevante es la extensión del trabajo. ¿Quién valora los procesos de asimilación y acomodación del conocimiento?, ¿Quien evalúa el proceso escritor?, son interrogantes cuyas respuestas no involucran directamente al docente porque, según estos imaginarios pedagógicos, no es del todo su responsabilidad el aprendizaje de los educandos.

Al respecto, Jan Renkema (1999), analizando la evaluación de la calidad del texto, plantea que "ningún estudio ha demostrado una correlación clara entre la longitud promedio de la unidad terminada y la calidad del texto"; de igual forma, afirma que "la investigación acerca de la calidad del texto se ha visto también dificultada por el hecho de que las apreciaciones con respecto al discurso pueden variar ampliamente: los juicios evaluativos sobre la calidad no son muy fiables”. Sin embargo, autores como: Paul Diederich (1974) e Inghard Langer, Friedermann Shulz von Thun y Reinhard Tausch (1974), construyeron modelos evaluativos sobre la calidad del texto.

Paul Diederich (1974) elaboró un modelo evaluativo con el que es posible efectuar juicios de calidad fiables a partir de una investigación en la cual hizo que cincuenta lectores de diversas esferas de la sociedad: docentes de lengua, abogados, editores, empresarios, gerentes, entre 
otros, evaluaran trescientos ensayos de universitarios de primer año. Los hallazgos presentaron un variado espectro de juicios evaluativos, así, se evidenciaron diferentes tendencias en la manera como se realizaban los juicios; de esta forma, las valoraciones pudieron reducirse a cinco ítems: ideas, mecánica, organización, redacción y sentido estético o estilo, factores que fueron ampliados con base en otra investigación realizada en Italia, con ello, ítems como: uso, puntuación, ortografía y caligrafía, también hicieron parte del modelo de evaluación de la calidad de Diederich.

Por su parte, los alemanes Inghard Langer, Friedermann Shulz von Thun y Reinhard Tausch (1974) elaboraron un modelo de evaluación compuesto por factores opuestos: sencillez estilística vs. complejidad, estructura vs. caos, concisión vs. verborrea y atracción vs. tedio. De esta manera, los dos modelos expuestos plantean categorías, de las cuales algunas pueden ser desarrolladas por los docentes en la evaluación de la producción textual y discursiva.

El discurso evaluativo finaliza con la expresión: “Trabajo muy DEFICIENTE" que por su fuerza de enunciación semántica y pragmática desde el registro en mayúscula subrayado, refiere acepciones de anulación y exclusión.

\section{A manera de conclusiones: ¿Estaba Confucio confundido?}

Aunque en el análisis de las muestras presentadas en este artículo se evidencian sólo algunas estrategias de dominación discursiva considero pertinente presentar en este apartado de conclusiones otras estrategias, hallazgos y propuestas de la investigación que cobran importancia.

Desarrollado el análisis crítico de las estructuras discursivas orales y escritas, que emplean algunos docentes de Lengua Castellana de los grados décimo y once, en determinadas instituciones educativas de Ibagué (Tolima-Colombia), para evaluar las actividades académicas escolares, puedo plantear que, pese a ser seleccionadas al azar de un 
corpus mayor, son todas estrategias discursivas impregnadas de abuso de poder, dominación, control, ridiculización, segregación, intimidación, ironización y mentira. Con lo anterior, no pretendo plantear que todos los discursos evaluativos se impregnan de dominación y abuso de poder, pues es posible que existan otras formas discursivas de evaluación más justas y menos dominantes. Las ideales para valorar los procesos de enseñanza y aprendizaje. Es en el estricto muestreo seleccionado para la investigación que se determinan estos hallazgos.

Entre las estrategias más empleadas se encuentran las de polarización discusiva de distanciamiento pronominal dominante, que afirman y re-afirman los roles sociales, cognitivos e institucionales y la posición vertical de cada sujeto educativo: docente-estudiantes = sujeto dominante-sujetos dominados, enunciadas no sólo en las interacciones orales sino también en las escritas.

Además, se emplean estrategias adverbiales de cantidad expresadas en el grado más alto o superlativación absoluta, que contribuyen al sentido de superioridad del sujeto dominante (docente); de ironía discursiva por alteración sintáctica; de identidad fonética o cacofonía parcial a partir de expresiones cotidianas que contribuyen al sentido ironizante y burlón del discurso evaluativo; de preguntasrespuestas que se convierten en el componente principal del proceso de interacción comunicativa en el aula, característica fundamental de la toma de turnos en el diálogo institucional. Preguntas-respuestas abiertas y cerradas que ejercen abuso de poder y control sobre los discursos y las acciones de los estudiantes; de control de selección de turnos en el diálogo institucional, así como estrategias de diálogo institucional bajo la modalidad de interacción en secuencias tripartitas: iniciativa: pregunta del docente, reacción: respuesta de los estudiantes, evaluación: valoración del docente sobre la actividad académica escolar del estudiante.

De igual forma, los docentes emplean estrategias de anulación total de las respuestas de los escolares; de introducción de ejemplos cotidianos en el discurso evaluativo; de referencias demostrativas por 
lejanía que indican un sentido despectivo hacia objetos, personas o acciones; de mitigación discusiva que reducen y enmascaran los niveles de agresividad, hostilidad e intimidación; de enunciación exhortativa que generan control físico sobre el escolar; de distanciamiento enunciativo que efectúan procesos de transposición de la persona para mitigar la fuerza ilocutiva real del discurso; de arrebatamiento del turno; de ridiculización orientadas al reconocimiento de acciones corporales como ademanes; de dirección deductiva, en donde el docente inicia una enunciación que evalúa la actividad académica escolar de varios estudiantes, un grupo de trabajo, y termina, en el mismo discurso evaluativo, refiriéndose y valorando a un solo escolar, y de cortesía que ocultan marcas de dominación, anulación y segregación.

También, es preciso especificar que emplean estrategias de distanciamiento y distinción escritor que diferencian registros $\mathrm{y}$ determinan los roles sociales e institucionales de los sujetos educativos: docentes-estudiantes; de escritura superpuesta que contribuyen al sentido de superioridad y dominación; de dominación y abuso de poder a través de la entonación y los registros en mayúscula, de mayor tamaño, subrayados y encerrados; de modalidad actitudinal evaluativa; de modalidad de mentira irónica dominante que expresan realidades diferentes y falsas a la realidad objetiva misma, y excluyen y segregan a los estudiantes y sus respectivas actividades académicas escolares.

Por su parte, los contenidos de las diferentes secuencias discursivas analizadas me permiten establecer una serie de visiones que conforman imaginarios pedagógicos y académicos particulares de estos docentes de Lengua Castellana; de esta manera, poseen imaginarios propios del modelo pedagógico tradicional o educación bancaria: concepción mecanicista de la producción cognitiva humana, que reduce estos procesos al sólo registro y grabación de datos o información; el docente es la autoridad en el aula de clase y es quien dicta la materia; el docente es el ejemplo a seguir y la única fuente de 
conocimiento, y los estudiantes, seguidores del ejemplo y receptores pasivos de la fuente cognitiva; la disciplina es concebida desde la reprensión del estudiante que sirve de ejemplo a los demás escolares; si el estudiante, aparentemente, no desarrolla en forma adecuada una actividad académica escolar es sólo por su falta de escucha. La responsabilidad del proceso de aprendizaje recae únicamente en los estudiantes; visión tradicional de la calificación como elemento central de la evaluación.

De igual manera, los docentes expresan concepciones teóricas incompletas y en bajo grado confiables referidas a los pueblos aborígenes de la Península Ibérica y al origen del castellano, del plagio discursivo como robo y del resumen como actividad central para el abordaje de la obra literaria, además de poseer una visión cuantitativa y directamente proporcional de la escritura, es decir, a mayor número de páginas escritas mayores las posibilidades de un valoración positiva. De igual manera, presentan razones que no corresponden al aparente desacierto del escolar; establecen una inclinación hacia las prácticas y sucesos cotidianos y familiares de los estudiantes; no evalúan contenidos conceptuales y procedimentales, en menor grado actitudinales, sino otros aspectos como: ademanes, tiempo de entrega, confirmación del ingreso de un estudiante en el último momento de la recepción del trabajo. El discurso evaluativo, que valora una actividad realizada en grupo, posee bajos niveles de confiabilidad porque se direcciona a un solo estudiante. De esta forma, por más que el escolar sea el relator de la actividad, el discurso debe estar dirigido a todos los integrantes del grupo de trabajo.

Desde esta perspectiva, el poder que ejercen los docentes de lengua castellana, como ya he especificado, a través de sus discursos evaluativos orales y escritos es producto de la característica omnipresente del poder (Foucault, 1981; 1984; 1985), de sus posiciones sociales e institucionales legitimadas como educadores, que establecen por definición relaciones asimétricas de conocimiento y de estatus, y de las mismas lógicas del lenguaje y del discurso; por tal razón, el poder de estos agentes está 
basado en recursos sociales y lingüísticos como el conocimiento, el rol formador y el discurso. Como grupos hegemónicos tienen acceso activo y preferente a diversos elementos del evento de la comunicación: controlan las formas de interacción en el diálogo institucional, los tópicos, la distribución espacial, entre otras estructuras que marcan fuertes procesos abuso de poder y dominación.

Es por tal motivo que el Análisis Crítico del Discurso (ACD) resulta ser una perspectiva crítica de investigación pertinente en los estudios discursivos evaluativos, y en general en todas las producciones discursivas de los hombres y las mujeres, debido a que aporta elementos teóricos y metodológicos relevantes para comprender las lógicas sociales e ideológicas del discurso, que construidas desde elementos de dominación y abuso de poder semantizan y pragmatizan las interacciones lingüísticas de control, ridiculización, burla, intimidación, represión y manipulación, acciones sociales y discursivas que impiden el desarrollo autónomo, crítico, reflexivo y libertario de los estudiantes.

Por tanto, es necesario establecer y desarrollar acciones estratégicas para poder generar la transformación de los discursos impregnados de dominación y abuso de poder; como lo propongo en la investigación, pueden desarrollarse acciones en la escena educativa enfocadas a lograr dichos cambios: la conceptualización docente y escolar orientada hacia el Análisis del Discurso (AD) y el Análisis Crítico del Discurso (ACD); el desarrollo del pensamiento crítico y una ética autónoma formada en el reconocimiento de la diferencia; la descentralización del $\mathrm{AD}$ y el $\mathrm{ACD}$ en otros ámbitos escolares distintos al universitario; la estructuración didáctica del AD y el ACD y la inclusión del AD y el ACD como temáticas en los planes de asignatura de Lengua Castellana en la secundaria; y la superación de la idea de contraposición de poderes dominador-dominados.

En forma específica, la evaluación exclusiva de los contenidos: conceptuales, procedimentales y actitudinales, de la producción académica de los escolares; el establecimiento de altos niveles de 
confiabilidad evaluativa, es decir, altos grados de validez y conocimiento seguro y claro de lo que evalúan los docentes, y la transformación de la dominación y el abuso de poder en el discurso evaluativo, contribuyen también al cambio discursivo, y por ende, educativo y social. Así Confucio no estará más confundido.

Enviado em: abril de 2009 Aprovado em: dezembro de 2009 oscarivanorama@hotmail.com

\section{Referencias Bibliográficas}

Berrendoner, Alain. (1981). Eléments de pragmatique linguistique. Paris: Les Editions de Minuit.

Bolívar, Adriana. (2005). El análisis del discurso en los ámbitos político y académico. En: Ramírez Peña, Luís Alfonso y Acosta Valencia, Gladys Lucía. (Comps.). Estudios del Discurso en Colombia. Universidad del Medellín. ALED. Medellín.

Charadeau, Patrick. (1992). Grammaire du sens et de l'expression. Editorial Hachete. Paris.

Dabène, Louise. (1980). Le Dialogue Pedagogique: Un Discours de l'enferment. En: Essais sur le Dialogue. Grenoble: U. des Langues et Lettres.

Drew, Paul y Sorjonen, Marjal-Leena. (2000). Diálogo Institucional. En: van Dijk, Teun A. (Comp.). El Discurso como Interacción Social. Estudios Sobre el Discurso II. Una Aproximación Multidisciplinaria. Editorial Gedisa. Barcelona. Diccionario Enciclopédico Educativo Uno COATENAS. 2000.

Durandin, Guy. (1983). La mentira en la propaganda política y en la publicidad. Editorial Paidós. Barcelona.

Fairclough, Norman. (2003). El análisis crítico del discurso como método para la investigación en ciencias sociales. En: Wodak, Ruth, y Meyer, M. (Comps.) (2003). Métodos de análisis crítico del discurso. Barcelona: Gedisa. 
Fairclough, Norman y Wodak, Ruth. (2000). Análisis crítico del discurso. En: van Dijk, Teun A. El discurso como interacción social. Estudios sobre el discurso II. Una introducción multidisciplinaria. Editorial Gedisa. Barcelona.

Freire, Paulo. (1985). Pedagogía del oprimido. Editorial Siglo XXI. México.

Genette, Gerard. (1989). Palimpsestos. Madrid: Taurus.

Kerbratt-Orechioni, Catherine. (1984). L'énonciation. De la subjetivite dans le langage. Paris: Armand Colin.

Londoño Zapata, Oscar Iván. (2006). El análisis crítico del discurso (ACD), una actitud de resistencia. Entrevista a Teun A. van Dijk. En: Revista Latinoamericana de Estudios del Discurso (ALED). Volumen 6, № 1. Venezuela.

Londoño Zapata, Oscar Iván. (2007). Los estudios del discurso en Venezuela y América Latina. Un compromiso social, político y académico. Entrevista a la Dra. Adriana Bolívar. En: Revista Discurso \& Sociedad Vol. 1 (4) (www.dissoc. org). Teun A. van Dijk (Editor).

Martín Rojo, Luisa y otras. (1998). El análisis crítico del discurso: una mirada indisciplinada. En: Martín Rojo, Luisa y Whittaker, Rachel. Poder - Decir o El poder de los discursos. Madrid: Arrecife.

Mchoul, A. (1978). The organization of turns at formal talk in the classroom. Language in Society, 7.

Mchoul, A. (1990). The organization of repair in classroom talk. Language in Society, 19.

Mehan, Hugh. (1979). Laerning Lessons. Social Organization in the Classroom. Harvard University Press, Cambridge University Press, Cambridge MA.

Meyer, Michael. (2003). Entre la teoría, el método y la política: la ubicación de los enfoques relacionados con el ACD. En: Wodak, Ruth y Meyer, Michael. (Comps.) (2003). Métodos de análisis crítico del discurso. Barcelona: Gedisa.

Pardo Abril, Neyla Graciela. (2001). Análisis del Discurso: una lectura de la cultura. En: Lenguaje y Cognición. Universos Humanos. Bogotá: Ediciones Universidad de Salamanca. Instituto caro y Cuervo.

Renkema, Jan. (1999). Introducción a los estudios sobre el discurso. Barcelona: Editorial Gedisa.

Sinclair, J. McH y Coulthard, R. M. (1975). Towards an analysis of discourse. Londres: Oxford U. P.

Van Dijk, Teun A. (1983). La ciencia del texto. Madrid: Paidós. 
Van Dijk, Teun A. (1985). Handbook of discourse análisis. Vol.1. London Academic Press.

Van Dijk, Teun A. (1990). La noticia como discurso. Comprensión, estructura y producción de la información. Editorial Paidós. Barcelona.

Van Dijk, Teun A. (1990). La ciencia del texto. Editorial Paidós. Barcelona.

Van Dijk, Teun A. (1993). Elite, discourse and racism. Newbury Park, CA: Sage.

Van Dijk, Teun. A. (1994). Conferencias. En: Cuadernos Maestría en Lingüística. Escuela de Ciencias del Lenguaje y Literatura. Universidad del Valle. Cali.

Van Dijk, Teun. A. (2000). Ideología. Una aproximación multidisciplinaria. Editorial Gedisa. Barcelona.

Van Dijk, Teun A. (2000). El discurso como estructura y proceso. Estudios del discurso: Introducción multidisciplinaria I. Editorial Gedisa. Barcelona.

Van Dijk, Teun A. (2000). El discurso como interacción social. Estudios sobre el discurso II. Una introducción multidisciplinaria. Editorial Gedisa. Barcelona. Van Dijk, Teun A. y Antena Digital. (2001). El análisis crítico del discurso y el pensamiento social. Antena Digital 1.

Van Dijk, Teun A. (2003). Ideología y discurso. Ariel Lingüística. Barcelona.

Van Dijk, Teun A. (2003). La multidisciplinariedad del análisis crítico del discurso: un alegato a favor de la diversidad. En: Wodak, Ruth y Meyer, Michael. (Comps.) (2003). Métodos de análisis crítico del discurso. Editorial Gedisa. Barcelona.

Van Dijk, Teun A. (2004). Discurso y Dominación. 25 años de Análisis Crítico del Discurso. En: Grandes conferencias en la Facultad de Ciencias Humanas. Universidad Nacional de Colombia. Facultad de Ciencias Humanas.

Voloshinov, Valentin Nikólaievich. (1998). El marxismo y la filosofía del lenguaje. Los principales problemas del método sociológico en la ciencia del lenguaje. Alianza Editorial.

Wodak, Ruth. (2003). De qué trata el análisis crítico del discurso (ACD). Resumen de su historia, sus conceptos fundamentales y sus desarrollos. En: Wodak, Ruth., y Meyer, Michael. (Comps.) (2003). Métodos de análisis crítico del discurso. Editorial Gedisa. Barcelona.

Wodak, Ruth y Meyer, Michael. (Comps.) (2003). Métodos de análisis crítico del discurso. Editorial Gedisa. Barcelona. 